\title{
sciendo
}

\section{Mental Toughness Characteristics of Male University Athletes in Relation to Contextual Factors}

\author{
by \\ Elijah Rintaugu', Francis Mwangi², Nancy Andanje', Xiaojie Tian ${ }^{3}$, \\ Noriyuki Fuku ${ }^{4}$, Tetsuhiro Kidokoro ${ }^{5}$
}

\begin{abstract}
Mental toughness is a psychological construct related to successful performance in academics, management, and sports among other sectors. However, studies on the determinants of mental toughness with respect to different human endeavours have remained inconclusive. This study explored mental toughness characteristics of male university athletes in selected sports in relation to contextual factors of athletes' age, playing experience, year of study, and the type of sport. The Mental Toughness Questionnaire (MTQ48) was used to collect data from male university athletes ( $n$ $=140$ ). Results of this study showed significant difference in the following components of MT: lower scores in challenge $(p=.015)$, emotional control $(p=.005)$, and life control $(p=.002)$ among athletes with shorter playing experience, and higher scores in life control $(p<.001)$, emotional control $(p=.021)$, and confidence in abilities $(p=.009)$ in handball as compared to soccer players. Soccer players had significantly higher scores in the challenge component $(p=.038)$ of mental toughness as compared to handball players. It was concluded that playing experience and the type of sport influenced characteristics of mental toughness among university athletes. Coaches, trainers, and sports psychologists need to consider these contextual factors to optimize mental toughness of athletes. Future studies should explore how specific contextual factors influence training environments and outcomes, as well as how stakeholders can leverage on the relationships between playing experience, the type of sport and mental toughness to augment athletes' mental toughness and sports performance.
\end{abstract}

Key words: challenge, commitment, confidence, emotional control, life control.

\section{Introduction}

Mental toughness (MT) is considered to be a multifaceted psychological construct constituting cognitive, affective, and behavioural dimensions (Connaughton and Hanton, 2009; Gucciardi, 2012). This concept is associated with increased stress resilience, successful stress management, and psychological well-being (Gerber et al., 2012). Clough et al. (2002) affirmed that mental toughness is composed of subscales of challenge (associated with performing well in challenging situations), commitment (not giving up under pressure), life, emotional control (perceived high control over the outcomes of one's performance), confidence in abilities, and interpersonal confidence (associated with unshakable belief in abilities). Studies have shown that mental toughness is a strong antecedent of performance in many human endeavours including academics, management, and sports (McGeown et al., 2015). The term "mental toughness" is used by athletes, coaches, sports psychologists, and sports commentators to refer to an athlete's disposition and ability to deal effectively with challenges, stressors, and pressure in sports (Jones, 2002; Meggs et al., 2014). It is the

1 - Department of Recreation and Sports Management, Kenyatta University, P O Box 43844 - 00100, Nairobi, Kenya.

2 - Department of Physical Education, Exercise and Sports Science, Kenyatta University, P O Box 43844 - 00100, Nairobi, Kenya.

3 - Faculty of Health and Sport Sciences, University of Tsukuba, 1-1-1 Tennodai, Tsukuba, Ibaraki 305-8574, Japan.

4 - Graduate School of Health and Sport Sciences, Juntendo University, 1-1 Hiraka-gakuendai, Inzai, Chiba, 270-1695, Japan.

5 - Faculty of Sport Science, Nippon Sport Science University, 7-1-1 Fukasawa, Setagaya, Tokyo 158-8508, Japan. 
ability to consistently perform towards the upper range of talent and skill regardless of competitive circumstances (Loehr, 1995). Furthermore, mental toughness has been defined as having the natural or developed psychological edge that enables an athlete to generally cope better with many demands of sports, such as stiff competition, hard training, and a strict lifestyle (Gould et al., 2002; Jones, 2002).

The existing studies have suggested that mentally tough athletes are characterized by selfbelief, self-esteem, desire, motivation, willpower, control, courage, focus and concentration, determination, commitment, consistency, high levels of optimism, and confidence (Connaughton \& Hanton, 2009; Gucciardi, 2012; Jones, 2002). Therefore, mental toughness is a desirable characteristic among athletes as they need to undergo hard training and face tough competition. Scholars have affirmed that mental toughness is one of the most important psychological characteristics related to successful outcomes in elite sport (McGeown et al., 2015). Previous studies have also shown that mental toughness varies based on the athletes' age, gender, the type of sport, and playing experience (Connaughton et al., 2010; Cowden and MeyerWeitz, 2016; Gerber et al., 2012; Thelwell et al., 2005). Mental toughness is also related to other psychological constructs like self-concept, mental imagery, and team cohesion, which are important with respect to positive outcomes in the sports field (Clough et al., 2002; Crust et al., 2014; Levy et al., 2006; Meggs et al., 2014).

With regard to gender, studies have found that male athletes score significantly higher than female athletes on mental toughness, confidence, and control (Crust et al., 2014; Gerber et al., 2012; Nicholls et al., 2009). This is attributed to the fact that male athletes are more confident in their athletic (physical) abilities than females (Todd and Kent, 2003). Other scholars have attributed these differences to the process of socialization (Nicholls et al., 2009) or to the differences in perception and cognition that affect selected mental toughness components. It has also been argued that male athletes are predisposed to have more mental toughness due to the presence of higher levels of testosterone which may dominate over cortisol (stress hormone), leading to increased feelings of power and tolerance for risk, which may enable them to perform well under pressure (Carney et al., 2010). On the other hand, other studies have shown that male and female athletes do not differ in mental toughness scores or selected mental toughness components. Some studies based on potentially large male and female sampling variances suggest the absence of differences in this domain (Crust and Swann, 2013).

The existing studies have not been consistent regarding whether the age of athletes has an impact on their mental toughness. On the one hand, Cowden and Meyer-Weitz (2016) found significant differences in mental toughness based on age and length of participation in tennis among South African tennis players. Older age groups and athletes with longer playing experience tended to report higher levels of total mental toughness, constancy, and control as compared to those of younger age groups and less experienced athletes. Connaughton et al. (2010) opined that mental toughness developed over time through a series of early, middle, later, and maintenance years. Nicholls et al. (2009) also suggested that levels of mental toughness increased with age. On the other hand, Crust and Keegan (2010) reported that mental toughness was not associated with age and that only scores of selected components such as emotional control were significantly correlated with age. Gould et al. (2002) found that mental toughness of elite athletes developed over long periods of time and was influenced by a wide range of individuals such as teachers, parents, and coaches. The environment has also been said to play an important role in the development of the attributes related to mental toughness. Motivational climate, parental influence, upbringing, and exposure to tough (competitive) environments are important ingredients in the development of mental toughness (Bull et al., 2005; Thelwell et al., (2005). Thelwell et al. (2005) found that elite soccer players believed varying environments and experiences during their formative years contributed to their development of mental toughness.

Findings related to the relationship between playing experience and mental toughness vary. The contentious point is whether mental toughness is fostered through increased levels of competitive sport involvement or 
whether mentally tough individuals are simply more inclined to attain sporting excellence. Nicholls et al. (2009) found that levels of total mental toughness increased with increasing sport playing experience, such that athletes competing at higher levels might exhibit superior mental toughness. Gould et al. (2002) studied psychological characteristics of Olympic champions and identified mental toughness as a significant contributor to sports performance enhancement.

Jones (2002) asserted that, while athletes possibly possessed inherited characteristics which related to "natural" mental toughness, it was also possible for athletes to develop mental toughness through learning new skills. As different sports require different psychological preparation and attributes, Asamoah (2013) examined the role of mental toughness, psychological skills, and team cohesion in soccer performance among male players and found no significant differences in any of the mental toughness and psychological skill scores between successful and less successful teams. Kuan and Roy (2007) found significant differences in self-confidence and negative energy control scores among Wushu athletes.

Regarding other psychological constructs, mental toughness has been significantly correlated with positive self-concept (Meggs et al., 2014), self-talk, emotional control and relaxation strategies (Crust and Azadi, 2010), imagery use, and cognitive planning tasks (Clough et al., 2002), as well as academic grades and progress (Crust et al., 2014). Levy et al. (2006) reported that athletes who were more mentally tough perceived their injury to be less severe and were also less susceptible to further injury than athletes with lesser mental toughness. They concluded that individuals with higher mental toughness were better able to cope with pain during rehabilitation.

It is apparent from the above mentioned studies that the development of mental toughness is likely to be influenced by environmental, cultural, and contextual factors. With most of the studies conducted in Western and developed countries, there was a need to explore the status and factors affecting athletes' mental toughness in different settings. Thus, the purpose of this study was to evaluate mental toughness of university athletes participating in national university sports championships in Kenya. It was hypothesized that mental toughness would not differ significantly based on the type of sport, age, and playing experience. Findings of this study may be useful to stakeholders in the sports fraternity such as university student-athletes, coaches, trainers, and university administrators.

\section{Methods}

Research design, study setting, and sampling of participants

A descriptive survey design was used in this study. The target population was studentathletes competing in university national sports championships. Data were collected from male university student-athletes who were participating in a national inter-university sports championship organized by the Kenya University Sports Association. Stratified random sampling procedures were employed to select participants for this study from among 350 male soccer and handball players. A total of 140 sampled participants (handball; $n=57,40.71 \%$ and soccer; $n=83,59.29 \%$ ) took part in the study. The two sports were selected as they were the most popular team sports among the study population.

Data collection procedures, instruments, and analyses

Authority to conduct the study was sought from the host university and the relevant sports governing body. Student-athletes were informed about the study objectives. They were also informed that their participation in the study was voluntary and that they could withdraw from the study at any time with no consequences. Informed consent forms were signed by those who agreed to participate in the study. Questionnaires were administered to the studentathletes immediately after their league matches. The targeted sample size was 184 (from a population of 350 male soccer and handball players, $95 \%$ confidence interval, and $5 \%$ margin of error) (Qualtrics, 2020). However, only 140 student-athletes' questionnaires were processed. This was a return rate of $76.10 \%$, which was considered acceptable for the study.

Data collection involved the use of a questionnaire which consisted of two sections; Section A sought the athletes' demographic information such as age, the type of sport, year of study, and playing experience. Section B consisted of the Mental Toughness Questionnaire (MTQ48) 
which included 48 items to assess athletes' mental toughness (Clough et al., 2015). The MTQ48 has six subscales, comprising challenge (8 items), commitment (11 items), emotional control (7 items), life control (7 items), confidence in abilities (9 items), and interpersonal confidence (6 items). The 48 items were rated by participants on a 5point Likert scale ranging from 1 (strongly disagree) to 5 (strongly agree). The MTQ48 has high overall test-retest reliability ranging from 0.80 to 0.90 as reported in previous studies by Clough et al. (2002), Crust and Clough (2005), and as corroborated by Middleton et al. (2004). The 5point Likert scale data were transformed to linear Percentage of Maximum Possible (POMP) scores as recommended by Cohen et al. (1999).

Data were coded and analysed with statistical package for social sciences (SPSS) Version 20 software. The Shapiro-Wilk test of normality was used to examine the distribution of dependent variables' data. The results indicated that most of the variables' (with the exception of commitment and life control) data were significantly different from a normal distribution $(p<.05)$. This informed the choice of nonparametric statistical tools for data analyses. Descriptive scores of frequencies, percentages, and means and medians were used to present summarized information, while the MannWhitney U test and the Kruskal-Wallis test were used to compare data sets across independent variables.

\section{Results}

The analysis of participants' demographic data showed that $4.28 \%$ of participants were aged between 16 and 18 years $(n=6), 47.1 \%$ between 19 and 21 years $(n=66), 37.1 \%$ between 22 and 24 years $(n=52)$, and $10.7 \%$ were older than 24 years $(n=15)$. Regarding the year of study, the largest portion of the university student-athletes was in their third year of study $(n=50 ; 35.7 \%)$, followed by participants in the second year of study $(n=45$; $32.1 \%)$. The number of participants in the first year and fourth year of study followed in decreasing order (with $n=26,18.6 \%$ and $n=17$, $12.1 \%$, respectively). Athletes involved in the study practiced handball $(n=57 ; 40.71 \%)$ and soccer $(n=83 ; 59.29 \%)$. With regard to athletes' playing experience in the university team, the majority of participants had played for the university team for two years $(n=52 ; 37.1 \%)$ followed by those who had played for three years ( $n=46 ; 32.9 \%$ ). The means, standard deviations, and median statistics regarding the athletes' scores on different components of mental toughness are presented in Table 1. The results show that athletes' mean scores regarding different components of mental toughness were highest in the challenge component followed by the mean scores for commitment, emotional control, interpersonal confidence, confidence in abilities, and life control in decreasing order.

The correlational analyses of the scores from the various components/subscales of mental toughness showed significant correlations for most combinations of the component pairs, as shown in Table 2. Life control and confidence in abilities had a significant correlation with all the other components at $p<.001$, except the challenge component which did not show a significant correlation with any of the other components. Emotional control had significant correlations with commitment, life control, and confidence in abilities at $p<.001$ as well as with interpersonal confidence at $p<.05$. Commitment recorded a significant correlation with emotional control, life control, and confidence in abilities at $p<.001$. Interpersonal confidence showed significant correlations with life control and confidence in abilities at $p<.001$, as well as with emotional control at $p<.05$.

This study aimed to establish whether mental toughness differed significantly based on athletes' age, the type of sport, and playing experience. Comparisons of scores from the different components of mental toughness across athletes' age groups conducted using the KruskalWallis test showed no significant differences $(p>$ .05). Comparisons between mean scores of soccer and handball athletes' mental toughness components/subscales performed using the Mann-Whitney U test are shown in Table 3. In this regard, the results showed that handball players had significantly higher mean scores than soccer players in the components of life control $(p<.001)$, confidence in abilities $(p=.009)$, and emotional control $(p=.021)$. However, soccer players had significantly higher mean scores than handball players in the challenge $(p=.038)$ component. The scores of the commitment component did not differ significantly between athletes of the two 
sports.

Comparisons of different components of mental toughness across the year of study using the Kruskal-Wallis test showed a significant difference in life control with a test statistic value of 13.409, $p=.020$ (two-tailed). However, post-hoc tests performed using the Dunn's test showed no significant difference. The pairwise comparison indicated that athletes in the first year of study recorded lower mean ranks for this component of mental toughness. Table 4 shows comparisons of the different components of mental toughness according to playing experience, using the Kruskal-Wallis test and subsequent post-hoc tests.

Considering playing experience, significant differences were found in the components of challenge $(p=.014)$, emotional control $(p=.007)$ and life control $(p<.001)$. Further analyses using Dunn's post-hoc tests showed that athletes who had played for one year had significantly lower means in the components of challenge $(p=.015)$, emotional control $(p=.005)$, and life control $(p=.002)$. Commitment and confidence in abilities showed marginal significance with the Kruskal-Wallis test; however, post-hoc tests using the Dunn's test revealed that no pairs were significantly different. Furthermore, interpersonal confidence recorded no significant differences (Table 4 ).

Table 1

Descriptive statistics of the mean POMP score, standard deviations and median score on the mental toughness sub-scales $(n=140)$

\begin{tabular}{lcccc}
\hline Mental Toughness sub-scales & \multicolumn{2}{c}{ Mean } & Std. Deviation & Median \\
& Statistic & Std. Error & Statistic & Statistic \\
\hline Challenge & 80.335 & 0.706 & 8.352 & 81.250 \\
Commitment & 69.740 & 0.953 & 11.280 & 70.455 \\
Emotional Control & 67.679 & 1.158 & 13.698 & 67.857 \\
Life Control & 59.439 & 1.368 & 16.184 & 57.143 \\
Confidence in Abilities & 63.095 & 1.315 & 15.558 & 63.889 \\
Interpersonal Confidence & 67.702 & 1.348 & 15.939 & 66.667 \\
\hline
\end{tabular}

Table 2

Correlations between mental toughness component sub-scales scores $(n=140)$

\begin{tabular}{llllllll}
\hline Mental Toughness Component & Spearman's rho & CH & CO & EC & LC & CA & IC \\
\hline \multirow{2}{*}{ Challenge (CH) } & rho & 1.000 & .151 & .121 & .073 & .074 & .133 \\
& Sig. (2-tailed) &. & .075 & .156 & .394 & .385 & .117 \\
Commitment (CO) & rho & .151 & 1.000 & $.303^{* *}$ & $.328^{* *}$ & $.292^{* *}$ & .150 \\
& Sig. (2-tailed) & .075 &. & .000 & .000 & .000 & .078 \\
Emotional Control (EC) & rho & .121 & $.303^{* *}$ & 1.000 & $.486^{* *}$ & $.484^{* *}$ & $.217^{*}$ \\
& Sig. (2-tailed) & .156 & .000 &. & .000 & .000 & .010 \\
\multirow{3}{*}{ Life Control (LC) } & rho & .073 & $.328^{* *}$ & $.486^{* *}$ & 1.000 & $.684^{* *}$ & $.294^{* *}$ \\
& Sig. (2-tailed) & .394 & .000 & .000 &. & .000 & .000 \\
Confidence in Abilities (CA) & rho & .074 & $.292^{* *}$ & $.484^{* *}$ & $.684^{* *}$ & 1.000 & $.466^{* *}$ \\
& Sig. (2-tailed) & .385 & .000 & .000 & .000 &. & .000 \\
\multirow{2}{*}{ Interpersonal Confidence (IC) } & rho & .133 & .150 & $.217^{*}$ & $.294^{* *}$ & $.466^{* *}$ & 1.000 \\
& Sig. (2-tailed) & .117 & .078 & .010 & .000 & .000 &. \\
\hline
\end{tabular}

${ }^{*}$ Correlation is significant at the 0.05 level (2-tailed).

${ }^{* *}$ Correlation is significant at the 0.001 level (2-tailed). 
Table 3

Comparisons between soccer and handball players' mental toughness component sub-scales scores using the Mann Whitney $U$ test $(n=140)$

\begin{tabular}{lcccccc}
\hline $\begin{array}{l}\text { Mental Toughness } \\
\text { sub-scales }\end{array}$ & \multicolumn{4}{c}{ Mean Rank } & \multicolumn{3}{c}{ Test Statistic } & $\begin{array}{l}\text { Sig. } \\
\text { (2-tailed) }\end{array}$ \\
\hline Challenge & 76.36 & 83 & 61.97 & 57 & $2,851.500$ & $.038^{*}$ \\
Commitment & 68.08 & 83 & 74.02 & 57 & $2,165.000$ & .394 \\
Emotional Control & 63.95 & 83 & 80.04 & 57 & $1,821.500$ & $.021^{*}$ \\
Life Control & 60.42 & 83 & 85.18 & 57 & $1,528.500$ & $.000^{* * *}$ \\
$\begin{array}{l}\text { Confidence in } \\
\text { Abilities }\end{array}$ & 63.14 & 83 & 81.22 & 57 & $1,754.500$ & $.009^{* *}$ \\
$\begin{array}{l}\text { Interpersonal } \\
\text { Confidence }\end{array}$ & 72.26 & 83 & 67.94 & 57 & $2,511.500$ & .622 \\
\hline
\end{tabular}

"Significant at $p<.05$ (2-tailed). ${ }^{* *}$ Significant at $p<.01$ (2-tailed).

${ }^{* * * *}$ Significant at $p<.001$ (2-tailed).

Table 4

Comparisons of athletes' mental toughness component subscales' scores across playing experience using the Kruskal-Wallis test and the Dunn's post-hoc test $(n=140)$

\begin{tabular}{lcc|cccc}
\hline $\begin{array}{l}\text { Mental Toughness } \\
\text { subscales }\end{array}$ & \multicolumn{4}{c|}{ Kruskal-Wallis test } & \multicolumn{4}{c}{ Dunn's test/post-hoc pairwise comparisons } \\
\cline { 2 - 7 } & $\begin{array}{c}\text { Test } \\
\text { statistic }\end{array}$ & $\begin{array}{c}\text { Sig. } \\
\text { (two- } \\
\text { tailed) }\end{array}$ & Sig. Pairs & $\begin{array}{c}\text { Std. Test } \\
\text { Statistic }\end{array}$ & $\begin{array}{c}\text { Sig. } \\
\text { (two- } \\
\text { tailed) }\end{array}$ & $\begin{array}{c}\text { Adj.Sig. } \\
\text { (two- } \\
\text { tailed) }\end{array}$ \\
\hline Challenge & 12.509 & .014 & $1^{*}-2$ & -2.690 & .002 & .015 \\
Commitment & 11.063 & $.026^{\mathrm{a}}$ & none & - & - & - \\
Emotional Control & 14.181 & .007 & $1^{* *}-2$ & -3.460 & .001 & .005 \\
Life Control & 20.108 & .000 & $1^{* *}-2$ & -3.767 & .000 & .002 \\
Confidence in Abilities & 11.556 & $.021^{\mathrm{a}}$ & $\begin{array}{c}1^{* *}-3 \\
\text { none }\end{array}$ & -4.138 & -000 & .000 \\
$\begin{array}{l}\text { Interpersonal } \\
\text { Confidence }\end{array}$ & 3.868 & $.424^{\mathrm{b}}$ & none & - & - & - \\
\hline
\end{tabular}

* Significantly lower at $p<.05 .{ }^{* *}$ Significantly lower at $p<.01 .{ }^{* * *}$ Significantly lower at $p<.001 .{ }^{a}$ The Kruskal-Wallis test showed marginal significance, but post-hoc tests using the Dunn's test showed that no pairs were significantly different. ${ }^{b}$ No significant differences were recorded with the Kruskal-Wallis test.

\section{Discussion}

The purpose of this study was to determine whether mental toughness of university athletes in selected sports was mediated by age, year of study, the type of sport, and playing experience. In the global scale of mental toughness, athletes scored high on the components of challenge, commitment, confidence in abilities, and emotional control, while the components of interpersonal confidence and life control had the lowest scores, in decreasing order.

Findings of this study indicate that athletes' mental toughness scores did not differ based on their age. These results partially agree with the findings of Crust and Keegan (2010) that the global scores on mental toughness were not associated with age and that only selected 
components were correlated with age. On the other hand, other studies have indicated greater levels of mental toughness with increasing age (Gould et al., 2002; Marchant et al., 2009; Nicholls et al., 2009). Cowden and Meyer-Weitz (2016) also reported significant differences regarding mental toughness among tennis players in South Africa based on the age and playing experience. The narrow chronological age gaps in the majority of the current study population may explain the lack of significant differences with regard to mental toughness and age.

Nonetheless, most of the components significantly differed with regard to playing experience. Shorter playing experience was associated with lower scores in the components of challenge, emotional control, and life control. The fact that most of the components showed significant differences with playing experience and no significant difference with age or the year of study suggests that relevant experience is important in the development of mental toughness in addition to chronological age. Thus, this adds credence to the results of other studies such as Cowden and Meyer-Weitz (2016) who reported significant differences in mental toughness among tennis players in South Africa based on the age and playing experience. Connaughton et al. (2010) contended that mental toughness developed over time through a series of early, middle, later, and maintenance years. This is in line with the proposed explanation that mental toughness can be enhanced in the socialization process through the influence of significant others. Therefore, it can be postulated that mental toughness is influenced by a combination of biological and environmental factors in which the athletes function.

Another finding of the current study is that athletes differed significantly on most of the subscales of mental toughness in favour of those with longer playing experience This finding is supported by previous studies which have shown that mental toughness increases with sports experience (Gould et al., 2002; Nicholls et al., 2009). Furthermore, Asamoah (2013) indicated that mental factors differentiated between athletes of particular competitive levels and that competitive experience was a crucial factor in the development and stabilization of mental skills of South African soccer players. A similar argument has been advanced by other studies which pointed out that elite athletes had higher levels of mental toughness, as mental toughness was enhanced through increased competitive environments where athletes had to constantly maintain sporting excellence (Bull et al., 2005; Thelwell et al., 2010).

Conventional wisdom alludes to the fact that mental toughness varies among athletes in different sports. This study compared mental toughness scores of athletes in handball and soccer, expecting variations. It was found that handball players had higher scores on most of the components of mental toughness except for the components of challenge and interpersonal confidence. Handball players had significantly higher mean ranks than soccer athletes in the components of emotional control, life control, and confidence in abilities. Within the context of mental toughness, control refers to the aspect of perceived high control over outcomes of performance, while confidence in abilities refers to the aspect of self-belief in executing difficult tasks or performing successfully under pressure (Clough et al., 2015). Thus, it was concluded that handball athletes had a higher level of mental toughness than soccer players in the study population. This raises the question as to why handball players achieved higher scores than soccer players in mental toughness. Cowden and Meyer-Weitz (2016) observed that the development of mental toughness in sport was dependent on the type of sport which athletes practiced. This could be attributed to the fact that different sports require excellence with respect to unique components of mental toughness. For example, handball athletes may require more control than soccer players based on the spacing between athletes. The sport is played in a smaller area and has a higher pace than soccer. Whether the difference in mental toughness is the result of the internal nature of the sport and/or the external socio-environmental circumstances that the particular sport is conducted in is subject to future studies. The findings of the current study may point to the need for athletes in one sport to explore different types of training and/or practice to increase competitive ability from experiences of another sport in order to enhance their mental toughness. This could be executed in the form of cross-training sessions designed with some 
mental training as one of the goals.

\section{Conclusions}

The current study concludes that mental toughness and the level of its components differ with different sports and relevant sporting experience. Coaches and psychologists need to consider the individual biographical and sport involvement characteristics of athletes in their efforts towards enhancing athletes' levels of mental toughness. Different components of mental toughness can be improved among university student-athletes through exposure to more competitive experiences coupled with relevant and elaborate mental training sessions. Higher-level competitions such as club and national competitions as well as cross-training should be explored as opportunities to enhance athletes' mental skills, including mental toughness. Further research should explore how the combination of specific contextual factors influences training environments and outcomes as well as how stakeholders can leverage on the relationships between playing experience and mental toughness, as well as between the type of sport and mental toughness to augment athletes' mental toughness in different sports. Future studies also need to compare mental toughness of athletes in individual and team sports, as well as between players of different playing positions within team sports.

\section{Acknowledgments}

The authors acknowledge with gratitude the respondents who volunteered to participate in the study and the cooperation of their team managers.

\section{References}

Asamoah, B. D. (2013). The role of mental toughness, psychological skills and team cohesion in soccer performance. https://scholar.sun.ac.za/bitstream/handle/10019.1/85729/asamoah_role_2013.pdf?isAllowed=y\&sequ ence $=2$

Bull, S. J., Shambrook, C. J., James, W., \& Brooks, J. E. (2005). Towards an understanding of mental toughness in elite English cricketers. Journal of Applied Sport Psychology, 17(3), 209 - 227. https://doi.org/10.1080/10413200591010085

Carney, D. R., Cuddy, A. J., \& Yap, A. J. (2010). Power posing: brief nonverbal displays affect neuroendocrine levels and risk tolerance. Psychological Science, 21(10), 1363-1368. https://doi.org/10.1177/0956797610383437

Clough, P. J., Earle, K., \& Sewell, D. (2002). Mental toughness: The concept and its measurement. In I. Cockerill (Ed.), Solutions in Sport Psychology (pp. 32-43). Thomson.

Clough, P., Perry, J., Crust, L., Strycharczyk, D., \& Rowlands, C. (2015). The MTQ48 Technical Manual. AQR International.

Cohen, P., Cohen, J., Aiken, L. S., \& West, S.G. (1999). The problem of units and the circumstance for POMP. Multivariate Behavioral Research, 34(3), 315-346. https://doi.org/10.1207/s15327906mbr3403_2

Connaughton, D., \& Hanton, S. (2009). Mental toughness in sport: Conceptual and practical issues. In S.D. Mellalieu, \& S. Hanton (Eds.), Advances in Applied Sport Psychology: A Review (pp. 317-346). Routledge.

Connaughton, D., Hanton, S., \& Jones, G. (2010). The development and maintenance of mental toughness in the world's best performers. Sport Psychologist, 24(2), 168-193. https://doi.org/10.1123/tsp.24.2.168

Cowden, R. G., \& Meyer-Weitz, A. (2016). Mental toughness in South African competitive Tennis: Biographical and sport participation differences. Journal of Sport and Exercise Psychology, 14(2), 152 167. https://doi.org/10.1080/1612197X.2015.1121509

Crust, L., \& Azadi, K. (2010). Mental toughness and athletes' use of psychological strategies. European Journal of Sport Science, 10(1), 43-51. https://doi.org/10.1080/17461390903049972

Crust, L., \& Clough, P. J. (2005). Relationship between mental toughness and physical endurance. Perceptual and Motor Skills, 100(1), 192-194. https://doi.org/10.2466/pms.100.1.192-194

Crust, L., \& Keegan, R. (2010). Mental toughness and attitudes to risk-taking. Personality and Individual Differences, 49(3), 164-168. https://doi.org/10.1016/j.paid.2010.03.026

Crust, L., \& Swann, C.F. (2013). The relationship between mental toughness and dispositional flow. European 
Journal of Sport Science, 13(2), 215-220. https://doi.org/10.1080/17461391.2011.635698

Crust, L., Earle, K., Perry, J., Earle, F., Clough, A., \& Clough, P. (2014). Mental toughness in higher education: Relationship with achievement and progression in first-year university sports students. Personality and Individual Differences, 69, 87-91. https://doi.org/10.1016/j.paid.2014.05.016

Gerber, M., Kalak, N., Lemola, S., Clough, P. J., Pühse, U., Elliot, C., Holsboer-Trachsler, E., \& Brand, S. (2012). Adolescents' exercise and physical activity are associated with mental toughness. Mental Health and Physical Activity, 5(1), 35-42. https://doi.org/10.1016/j.mhpa.2012.02.004

Gould, D., Dieffenbach, K., \& Moffett, A. (2002). Psychological characteristics and their development in Olympic champions. Journal of Applied Sport Psychology, 14(3), 172-204. https://doi.org/10.1080/10413200290103482

Gucciardi, D. F. (2012). Measuring mental toughness in sport: A psychometric examination of the psychological performance inventory-A and its predecessor. Journal of Personality Assessment, 94(4), 393-403. https://doi.org/10.1080/00223891.2012.660292

Jones, G. (2002). What is this thing called mental toughness? An investigation of elite sport performers. Journal of Applied Sport Psychology, 14(3), 205-218. https://doi.org/10.1080/10413200290103509

Kuan, G., \& Roy, J. (2007). Goal profiles, mental toughness and its influence on performance outcomes among Wushu athletes. Journal of Sports Science \& Medicine, 6(CSSI-2), 28-33.

Levy, A. R., Polman, R. C., Clough, P. J., Marchant, D. C., \& Earle, K. (2006). Mental toughness as determinant of beliefs, pain and adherence in sport injury rehabilitation. Journal of Sport Rehabilitation, 15(3), 245-254. https://doi.org/10.1123/jsr.15.3.245

Loehr, J. E. (1995). The new toughness training for sports: mental emotional physical conditioning from one of the world's premier sports psychologists. Plume.

Marchant, D. C., Polman, R. C., Clough, P. J., Jackson, J. G., Levy, A. R., \& Nicholls, A. R. (2009). Mental toughness: Managerial and age differences. Journal of Managerial Psychology, 24(5), 428-437. https://doi.org/10.1108/02683940910959753

McGeown, S. P., St.Clair-Thompson, H., \& Clough, P. (2015). The study of non-cognitive attributes in education: proposing the mental toughness framework. Educational Review, 68(1), 96-113. https://doi.org/10.1080/00131911.2015.1008408

Meggs, J., Ditzfeld, C., Golby, J. (2014). Self-concept organization and mental toughness in sport. Journal of Sports Sciences, 32(2), 101-109. http://doi.org/10.1080/02640414.2013.812230

Middleton, S. C., Marsh, H., Martin, A. J., Richards, G. E., \& Perry, C. (2004). Discovering mental toughness: a qualitative study of mental toughness in elite athletes. http://www.sectiononewrestling.com/discovering_mental_toughness.pdf

Nicholls, A., Polman, R., Levy, A., \& Backhouse, S. (2009). Mental toughness in sport: Achievement level, gender, age, experience and sport type differences. Personality and Individual Differences, 47(1), 73-75. https://doi.org/10.1016/j.paid.2009.02.006

Qualtrics (2020). Sample size calculator. https://www.qualtrics.com/blog/calculating-sample-size/

Thelwell, R., Such, B., Weston, N., Such, J., Greenless, L. (2010). Developing mental toughness: Perceptions of elite female gymnasts. International Journal of Sport and Exercise Psychology, 8(2), 170-188. https://doi.org/10.1080/1612197X.2010.9671941

Thelwell, R., Weston, N., Greenless, I. (2005). Defining and understanding mental toughness within soccer. Journal of Applied Sport Psychology, 17(4), 326-332. https://doi.org/10.1080/10413200500313636

Todd, S. Y., \& Kent, A. (2003). Student athletes' perception of self. Adolescence, 38(152), 659-667.

\section{Corresponding author:}

\section{Dr. Francis M. Mwangi,}

Senior Lecturer, Department of Physical Education, Exercise and Sports Science,

Kenyatta University, P O Box 43844 - 00100, Nairobi, Kenya.

Tel: +254722761379

Email: mwangi.francis@ku.ac.ke 